\title{
Effect of Sling Exercise on Muscle Activity and Pain in Patients with Rotator Cuff Repair
}

\author{
Jae-Woon Kim', Yong-Nam Kim² \\ 'Department of Physical Therapy, Graduate School, Nambu University; ${ }^{2}$ Department of Physical Therapy, Nambu University Gwangju, Korea
}

Purpose: This study was conducted to determine the effects of sling exercise on muscle activity and pain in patients with rotator cuff repair.

Methods: This research evaluated 20 rotator cuff repair patients, divided randomly between 10 controls and 10 in an experimental group who performed a sling exercise. Both the experimental and control groups underwent transcutaneous electrical nerve stimulation and performed continuous passive motion. Muscle activity was measured with a surface electromyograph and pain was measured with the visual analogue scale. The paired t-test was used to compare groups before and after the experiment. The independent t-test was conducted to assess differences in the degree of change between the two groups before and after the experiment.

Results: Within-group comparison of both the experimental and control group showed significant differences in muscle activity and pain. Comparison of the groups revealed significant differences in muscle activity between groups group, but not in pain.

Conclusion: These results indicate that sling exercise is effective for improving muscle activity of rotator cuff repair patients.

Keywords: Sling exercise, Muscle activity, Pain

\section{서 론}

일상 생활을 수행하기 위해 팔의 역할이 매우 중요하고' 그 중에서 어 깨관절은 우리 몸에서 운동 범위가 가장 크다. 그러나 위팔뼈 머리의 크기에 비해서 어깨뼈 소켓부분이 얕기 때문에 구조적으로 불안정 한 해부학적 구조를 가지고 있다. 특히 어깨 통증은 인구의 절반이 일 년에 한번은 경험할 정도로 흔하며, ${ }^{3} \mathrm{Shin}^{4}$ 의 연구에서는 어깨 통 증으로 인해 내원한 환자 총 4,079 명을 조사한 결과, 돌림근띠 질환이 $55 \%$ 로 가장 많았다고 보고하였다.

육체적 노동자나 반복적인 작업으로 인한 근골격계 질환 및 스포 츠 활동의 증가로 어깨에 있는 돌림근띠의 파열이 빈번히 발생한다. ${ }^{5}$ 돌림근띠란 가시위근, 가시아래근, 작은원근, 어깨밑근을 말하며, ${ }^{6}$ 돌 림근띠의 파열은 이 4 개의 힘줄이 파열되는 것을 말한다. 돌림근띠 파열은 일상 생활 장애를 일으키는 질환 중 하나이며, ${ }^{8}$ 극심한 통증 과 근 약화, 가동범위의 제한을 초래 할 수 있다.9

돌림근띠 파열의 치료방법으로는 수술적 방법과 비수술적 방법으 로 구분되며 비수술적인 방법으로는 약물요법과 물리치료, 증상을
유발시킬 수 있는 생활양식의 변화, 신장운동과 근력 강화운동이 고 려되고 4-6개월 이상 통증, 기능적 활동의 호전이 없다면 수술적인 치 료를 고려한다. ${ }^{10}$ 수술적 치료로 돌림근띠 봉합술을 시행하는데 봉 합술은 건과 뼈의 결합을 최대화하고 해부학적 구조공간을 정상으 로 만들기 위해 시행한다." 이 중 관절경 봉합술이 근 손상과 수술 흥 터, 수술 후 통증을 최소화 하여 환자들에게 만족을 주고 있어 재활 및 기능 회복이 빠르다고 보고되었다. ${ }^{12}$ 관절경 봉합술 후 재활에 있 어 일반적으로 초기 6주 동안 재건한 힘줄의 원활한 치유를 위하여 능동적 움직임을 금지하고 이후 점차 열린 사슬과 닫힌 사슬을 이용 하여 근육들의 기능회복에 초점을 맞춰 시행해야 한다고 권고하였 고, 기본적인 원칙으로는 수술 집도의의 판단 하에 힘줄과 뼈의 치유 가 확실하다고 확인되면 시행해야 한다는 견해가 일반적이다.13

돌림근띠 손상 환자의 어깨관절 기능의 회복을 위한 효과적인 재 활 프로그램을 제공하기 위해선 어깨 통증의 감소와 관절가동범위 향상 및 근력과 지구력의 관리가 필요하고 안정근들 사이의 균형적 인 조절 능력을 회복하는데 초점을 두어야 한다. ${ }^{14}$ 어깨관절에서의 운동성이 더욱 효율적으로 움직이기 위해서는 어깨뼈의 안정성이 확 
보되어야 한다. ${ }^{15}$ 어깨 안정화 운동은 어깨뼈가 중립위치에서 기능적 움직임을 수행할 수 있도록 설계된 운동 프로그램으로서 어깨뼈의 안정성을 높이고, 어깨뼈 주변 근육들의 정상적 길이-장력 관계를 회 복하기 위해 고안된 운동으로, ${ }^{16,17}$ 어깨관절 치료에 있어 어깨뼈의 안 정성이 가장 먼저 생성되어야 기능적인 동작들이 회복될 수 있다. ${ }^{18}$

어깨 안정화를 위한 방법 중 슬링운동은 흔들리는 줄과 불안정한 지 면에서 이루어지는 능동적인 운동으로 감각 및 운동의 통합 효과를 매 우 적절히 적용할 수 있는 치료적 접근법이다. ${ }^{19}$ 이를 통해 얻을 수 있는 효과는 연부조직 이완, 관절가동범위의 증가, 근육조직의 안정화, 근력 강화 등의 효과가 있다.20.21 선행연구에서 돌림근띠 파열 환자를 대상으 로 어깨 안정화 운동을 실시한 결과 위등세모근의 근 활성도가 감소되 고 아래등세모근과 앞톱니근의 근 활성도가 증가하였다고 하였고, ${ }^{22}$ 외 상 후 어깨관절낭염 환자에게 관절가동술과 슬링운동을 병행하여 치 료한 결과 통증이 감소되었다고 보고되었다.23 선행연구들을 통해 어깨 환자에게 슬링운동의 긍정적인 효과가 많이 보고가 되고 있지만, 어깨 수술 환자에 슬링운동의 영향을 알아보는 연구는 아직까지 부족한 실 정이다. 특히 돌림근띠 봉합술 환자에게 간접적으로 환측 손 쥐기 훈련 을 통한 효과에 대해 알아보는 연구들은 많지만 ${ }^{24,25}$ 슬링운동을 이용한 어깨 안정화 운동의 효과에 관한 연구는 미흡한 실정이다.

따라서 본 연구에서는 슬링운동이 돌림근띠 봉합술 환자의 근 활 성도와 통증에 미치는 영향을 알아보고 나아가 임상에서의 근거와 기초자료를 제공하는 데 목적이 있다.

\section{연구방법}

\section{1. 연구대상}

본 연구에 참여한 대상자는 20 명의 입원환자를 대상으로 슬링운동 군 10 명과 대조군 10 명으로 나누어 실험을 진행하였으며, 각 실험 대 상자들은 연구에 참여를 동의한 자와 돌림근띠 중 가시위근의 파열 진단을 받고 관절경 수술 후 6주 이상 경과한 자, 돌림근띠 파열 크기 가 1 이하의 소범위 손상자, 혈압. 맥박.호흡에 별다른 이상이 없는 자 로 무작위 선정하였다. 대상자 선정 시 돌림근띠 파열로 과거 수술을 받고 현재 재수술을 받은 자, 가시위근 이외의 다른 돌림근띠 근육이 파열된 자, 정신 질환이나 통증에 영향을 주는 복합적인 문제를 가진 자, 돌림근띠 파열 이외에 다른 질환이 있는 자, 신경손상이 있는 자 는 실험에서 제외하였다.

\section{2. 실험방법}

실험군의 슬링운동 프로그램은 팔에 슬링을 걸어 중력을 제거한 상 태에서 시행하였다. 운동방법은 엎드린 자세에서 환측 팔에 슬링을 걸고 어깨뼈 세팅 운동, 앉은 자세에서 양쪽 팔에 슬링을 걸고 어깨
들임 내밈 운동, 옆으로 누운 자세에서 환측 팔에 슬링을 걸고 어깨 굽힘.폄 운동, 누운 자세에서 환측 팔에 슬링을 걸고 어깨 벌림.모음 운동, 앉은 자세에서 환측 팔에 슬링을 걸고 어깨 수평외전·수평내 전 운동을 시행하였고 실험군의 운동프로그램은 1 일 40 분, 매주 3 회, 총 3주 동안 실시하였고 실험군과 대조군 모두 transcutaneous electrical nerve stimulator (TENS)와 continuous passive motion (CPM)을 1일 40 분, 매주 5 회, 총 3 주 동안 실시하였다.

\section{1) 측정도구 \\ (1) 표면 근전도 측정}

근 활성도는 표면 근전도 측정장비인 EMG BTS300 (BTS Company, Milano, Itary)을 사용하였다. 표면 근전도 신호에 대한 피부저항을 감 소시키기 위해 부착 부위의 털을 제거하고 가는 사포를 이용하여 각 질을 제거한 후 알코올 솜으로 문질러 피부를 청결히 한 후, 피부 표면 에 부착하고 전극과 근전도 기기를 연결하였다. 표면 근전도 전극은 위등세모근, 아래등세모근, 가시아래근, 앞톱니근에 부착하였으며, 위등세모근의 부착 위치는 7번 목뼈와 봉우리빗장관절을 연결하는 중심선의 뒤쪽 부위 힘살에 부착, 아래등세모근은 10 번 등뼈 가시위 돌기에서 $10 \mathrm{~cm}$ 정도의 위치에 부착하여 이에 형성된 선을 따라 바깥 위쪽 사선방향에 부착, 가시아래근은 어깨뼈 가쪽에서 어깨뼈가시 아래 $4 \mathrm{~cm}$ 밑에 부착, 앞톱니근은 5,6 번째 갈비뼈높이의 겨드랑이 중 심선의 뒤쪽 부위 힘살에 부착하였다. 수집된 근육별 근전도 신호는 $\% \mathrm{RVC}$ 로 정규화하여 reference voluntary contraction (RVC)을 사용하 였고 root mean square (RMS)로 처리하여 분석하였다. 대상자들의 RVC 기본값으로 활용하기 위해 의자에 편하게 앉은 자세에서 양팔 을 몸통 옆에 놓고 일정한 자세를 유지하게 하여 측정하였다. 자발적 기준 수축의 측정자세는 의자에 앉은 자세로 팔꿉관절을 편 상태에 서 어깨관절을 90 굽힘을 유지하게 하여 측정하였다. 5 초 동안 유지 할 때 근전도 신호를 수집하여 앞 1 초 구간과 뒤 1 초 구간을 제거하고 3 초 구간의 RMS 값을 구하였고, 이를 3 회 반복 측정하여 평균값을 측정하였다. 수집된 근전도 신호들은 특정동작 시 RMS 평균값을 기 준동작 시 RMS 평균값으로 나눠 백분율하여 $\% \mathrm{RVC}$ 값을 구하였다.

\section{(2) 통증 측정}

통증의 정도를 측정하기 위해 시각적 상사척도 (visual analogue scale, $\mathrm{VAS}$ )를 이용하여 평가하였다. 환자가 이해하기 쉽도록 하기 위해 0 에 서 10 까지 범위에서 통증의 정도를 환자 스스로 표시 하도록 하였다. 0 의 위치는 전혀 통증이 없는 상태이며, 10 의 위치는 통증이 가장 심한 상태이며, 수치가 낮을수록 통증 강도가 낮은 것을 의미한다. ${ }^{26} \mathrm{VAS}$ 의 검사-재검사 신뢰도(test-retest reliability)는 Li 등 ${ }^{27}$ 의 선행연구 결과 급 간내상관계수(intraclass correlation coefficient, ICC)는 $0.70-0.83$ 였다. 
(3) 분석방법

모든 자료는 SPSS ver 22.0 (SPSS, IBM, USA)를 이용하여 분석하였고 대상자의 일반적 특성을 알아보기 위해 기술 통계량을 사용하였다 실험 전과 후의 변화를 알아보기 위해 대응표본 t 검정(paired t-test)을 실시하였고, 실험 후 두 그룹 사이의 차이를 알아보기 위해 각 그룹의 실험 전. 후 차이에 대하여 독립표본 t검정(independent t-test)을 실시 하였다. 통계학적 유의수준은 0.05 로 하였다.

Table 1. General characteristics of the subjects

\begin{tabular}{lcc}
\hline & EG $(\mathrm{n}=10)$ & $\mathrm{CG}(\mathrm{n}=10)$ \\
\hline Gender (male/female) & $6 / 4$ & $5 / 5$ \\
Age (year) & $45.4 \pm 5.0$ & $44.6 \pm 4.8$ \\
Weight $(\mathrm{kg})$ & $69.3 \pm 10.9$ & $64.7 \pm 9.4$ \\
Height $(\mathrm{cm})$ & $167.5 \pm 8.1$ & $168.8 \pm 9.5$ \\
BMI $\left(\mathrm{kg} / \mathrm{m}^{2}\right)$ & $24.6 \pm 2.6$ & $23.8 \pm 1.9$ \\
\hline
\end{tabular}

\section{결 과}

\section{1. 연구대상자들의 일반적인 특성}

연구대상자는 성인 남녀 20명을 대상으로 슬링운동군의 성별은 남 자 6 명, 여자 4 명이었고 대조군의 성별은 남자 5 명, 여자 5 명이었다. 연 구 대상자의 일반적인 특성은 Table 1과 같다.

\section{2. 집단 내 슬링운동군의 \%RVC와 통증 변화비교}

슬링운동군의 집단 내 \%RVC 변화비교에서는 위등세모근에서 유의 하게 감소하였고 $(\mathrm{p}<0.05)$, 아래등세모근, 가시아래근, 앞톱니근에서 유의하게 증가하였다 $(\mathrm{p}<0.05)$. 통증에서는 유의하게 감소하였다 $(\mathrm{p}<0.05)($ Table 2$)$.

Mean \pm SD

Table 2. Comparison of the results of muscle activity and pain between pre and post intervention

\begin{tabular}{|c|c|c|c|c|c|}
\hline & Group & Pre & Post & $\mathrm{t}$ & $\mathrm{p}$ \\
\hline \multirow[t]{2}{*}{ Upper trapezius } & EG & $1199.8 \pm 108.4$ & $963.9 \pm 76.1$ & 17.057 & $0.000^{\prime}$ \\
\hline & CG & $1261.2 \pm 77.3$ & $1175.3 \pm 91.3$ & 12.735 & 0.000 \\
\hline \multirow[t]{2}{*}{ Lower trapezius } & EG & $431.6 \pm 31.7$ & $521.3 \pm 35.1$ & -9.634 & 0.000 \\
\hline & CG & $412.0 \pm 50.5$ & $450.2 \pm 51.0$ & -7.69 & 0.000 \\
\hline \multirow[t]{2}{*}{ Infraspinatus } & EG & $430.2 \pm 22.4$ & $505.4 \pm 31.3$ & -10.207 & 0.000 \\
\hline & CG & $426.7 \pm 48.0$ & $452.9 \pm 51.9$ & -5.741 & 0.000 \\
\hline \multirow[t]{2}{*}{ Serratus anterior } & $E G$ & $323.2 \pm 21.6$ & $441.6 \pm 41.0$ & -11.622 & $0.000^{*}$ \\
\hline & CG & $325.5 \pm 37.1$ & $359.8 \pm 49.9$ & -4.56 & $0.001^{\star}$ \\
\hline \multirow[t]{2}{*}{ Pain } & EG & $6.8 \pm 1.0$ & $3.1 \pm 0.6$ & 14.212 & 0.000 \\
\hline & CG & $7.4 \pm 0.7$ & $3.9 \pm 1.0$ & 10.247 & $0.001 *$ \\
\hline
\end{tabular}

All values are shown in mean \pm standard deviation.

*significant difference between pre- and post- test ( $p<0.05)$.

EG: experimental group, CG: control group.

Table 3. Comparison of the results of muscle activity and pain between the experimental and control groups

\begin{tabular}{|c|c|c|c|c|c|}
\hline & Group & $\mathrm{EG}$ & $C G$ & $t$ & $p$ \\
\hline \multirow[t]{3}{*}{ Upper trapezius } & Pre & $1199.8 \pm 108.4$ & $1261.2 \pm 77.3$ & -1.458 & 0.162 \\
\hline & Post & $963.9 \pm 76.1$ & $1175.3 \pm 91.3$ & & \\
\hline & Pre-Post & $-235.8 \pm 43.7$ & $-85.8 \pm 20.8$ & -9.928 & $0.000^{*}$ \\
\hline \multirow[t]{3}{*}{ Lower trapezius } & Pre & $431.6 \pm 31.7$ & $412.0 \pm 50.5$ & 1.041 & 0.312 \\
\hline & Post & $521.3 \pm 35.1$ & $450.2 \pm 51.0$ & & \\
\hline & Pre-Post & $89.2 \pm 29.4$ & $38.2 \pm 16.1$ & 4.751 & $0.000^{*}$ \\
\hline \multirow[t]{3}{*}{ Infraspinatus } & Pre & $430.2 \pm 22.4$ & $426.7 \pm 48.0$ & 0.208 & 0.838 \\
\hline & Post & $505.4 \pm 31.3$ & $452.9 \pm 51.9$ & & \\
\hline & Pre-Post & $75.1 \pm 23.2$ & $26.1 \pm 15.6$ & 5.31 & $0.000^{*}$ \\
\hline \multirow[t]{3}{*}{ Serratus anterior } & Pre & $323.2 \pm 21.6$ & $325.5 \pm 37.1$ & -0.174 & 0.864 \\
\hline & Post & $441.6 \pm 41.0$ & $359.8 \pm 49.9$ & & \\
\hline & Pre-Post & $118.2 \pm 23.7$ & $34.2 \pm 23.7$ & 7.331 & $0.000^{*}$ \\
\hline \multirow[t]{3}{*}{ Pain } & Pre & $6.8 \pm 1.0$ & $7.4 \pm 0.7$ & -1.521 & 0.146 \\
\hline & Post & $3.1 \pm 0.6$ & $3.9 \pm 1.0$ & & \\
\hline & Pre-Post & $-3.7 \pm 0.8$ & $-3.5 \pm 0.8$ & -1.897 & 0.076 \\
\hline
\end{tabular}

All values are shown in mean \pm standard deviation.

*significant difference between experimental and control group test $(p<0.05)$

EG: experimental group, CG: control group. 


\section{3. 집단 내 대조군의 \%RVC와 통증 변화비교}

대조군의 집단 내 \%RVC 변화비교에서는 위등세모근에서 유의하게 감소하였고 $(\mathrm{p}<0.05)$, 아래등세모근, 가시아래근, 앞톱니근에서 유의 하게 증가하였다 $(\mathrm{p}<0.05)$. 통증에서는 유의하게 감소하였다 $(\mathrm{p}<0.05)$ (Table 2).

\section{4. 집단 간 \%RVC와 통증 변화비교}

집단 간 $\% \mathrm{RVC}$ 변화비교에서는 위등세모근, 아래등세모근, 가시아래 근, 앞톱니근에서 유의한 차이가 있었고 $(\mathrm{p}<0.05)$, 통증에서는 유의한 차이가 없었다(Table 3).

\section{고 찰}

돌림근띠 파열은 어깨주변의 통증과 일상생활의 장애를 일으키는 가장 흔한 질병 중에 하나이며, 돌림근띠가 파열되어 보전적인 치료 에도 호전을 보기가 힘든 경우에는 통증완화와 기능회복 및 파열의 진행을 막기 위해 관절경 및 자기공명영상장치를 이용한 돌림근띠 봉합술이 보편적인 수술로 널리 사용되고 있고, 이러한 환자들에게 손상의 진단과 치료가 용이하게 되었다. 28,29 그러나 돌림근띠 봉합술 로도 복원할 때의 긴장도가 증가된다면 어깨관절의 구조 및 기능적 문제를 만들어낼 수 있고, ${ }^{30,31}$ 수술 후에 합병증으로 관절낭 단축으 로 오는 어깨관절의 수동움직임 제한과 근력 약화에서 오는 능동움 직임의 제한이 있을 수 있다. ${ }^{2}$ 그러므로 수술 후 재활의 목적은 질환 의 상태를 이해하여 추가손상을 방지하고, 교원질의 회복을 도모하 며 약해진 근력을 강화시켜 유착, 구축 등에 의해 감소된 관절운동을 회복하는 것이지만 봉합부위와 힘줄을 복원한 부위를 고려해서 적 용해야한다. ${ }^{12}$

본 연구의 목적은 돌림근띠 봉합술 환자를 대상으로 슬링운동이 돌림근띠 환자의 근 활성도, 통증에 어떠한 영향을 미치는지 확인하 기 위함이었다. 이를 위해 실험군에서는 슬링운동을 실시한 실험군, 일반적인 치료를 적용한 대조군으로 3 주 후의 변화를 비교하였다.

연구 결과 위등세모근, 아래등세모근, 가시아래근, 앞톱니근의 근 활성도 집단 내 비교에서 실험군과 대조군에서 유의한 차이가 있었 다 $(\mathrm{p}<0.05)$. 집단 간 비교에서 실험군의 위등세모근의 근 활성도는 대 조군에 비해 유의하게 감소하였고 아래등세모근, 가시아래근, 앞톱니 근의 근 활성도는 실험군이 대조군에 비해 유의하게 증가하였다 $(\mathrm{p}<0.05)$. 선행연구에서 어깨의 문제가 있는 환자들에게 앞톱니근, 아래등세모근과 같은 안정근의 근 활성이 떨어져있고 위등세모근이 과도하게 활성화되어, 이는 어깨 근육들의 불균형을 일으켜 통증까 지 유발시킨다고 하였다. ${ }^{33}$ Myung ${ }^{34}$ 은 돌림근띠 봉합술 환자 20명을 대상으로 슬링운동을 8 주간 시행한 결과 가시아래근의 근 두께가 중
재 전 $81.36 \pm 16.83 \mathrm{pt}$ 에서 $146.52 \pm 25.75 \mathrm{pt}$ 로 증가하였고 the American shoulder and elbow surgeons shoulder score (ASES) 비율척도에도 유의 하게 증가하여 어깨관절 기능이 향상되었다고 하였다. Jang등 35 은 어 깨충돌증후군 환자 20 명을 대상으로 슬링운동군과 등척성운동군을 나누어 6주간 운동을 실시한 결과 슬링운동군이 등척성운동군에 비 해 위등세모근, 아래등세모근, 앞톱니근의 근 수축 개시 시간이 빨라 졌으며, 통증 또한 슬링운동군이 $5.90 \pm 1.60$ score에서 $4.10 \pm 1.91$ score 로 등척성운동군에 비해 유의하게 감소하였다. 또한, 슬링을 이용하 여 안정된 지지면과 불안정한 지지면에서 팔굽혀펴기 운동 시 근 활 성도 차이를 비교한 연구에서 슬링을 이용한 불안정한 지지면에서 운 동을 할 때 앞톱니근의 근 활성을 증가시키고 위등세모근의 과활성화 를 감소시키는데 더욱 효과적이라고 하였다. ${ }^{36}$ 본 연구는 선행연구 결 과와 일치하였으며 슬링운동이 돌림근띠 봉합술 환자를 대상으로 근 활성도 증가에 긍정적인 영향을 미치는 것을 알 수 있었다.

어깨 통증의 집단 내 비교에서 실험군과 대조군에서 유의한 차이 가 있었지만 $(\mathrm{p}<0.05)$, 집단 간 비교에서의 통증은 실험군과 대조군에 서 유의한 차이가 없었다( $p>0.05)$. 선행연구에서 Jung $\mathrm{Ju}^{37}$ 의 연구에서 는 돌림근띠 파열 환자 12 명을 대상으로 8 주 동안 어깨 안정화 운동 을 한 결과 통증이 유의하게 감소하였다고 하였고, Burkhart등 38 은 어 깨통증이 있는 중년여성을 대상으로 슬링운동을 한 결과 통증이 유 의하게 감소하였다고 하였다. 또한, Yoon등 ${ }^{39}$ 은 관절경 수술환자에게 급성 재활치료로 저강도 어깨 안정화 운동을 적용했을 때 환자의 통 증이 유의하게 감소하였다고 하였다. 하지만, 본 연구에서는 실험군 과 대조군이 유의한 차이는 없었는데 기존의 선행연구들보다 실험 기간이 짧았기 때문에 이와 같은 결과가 발생한 것으로 생각된다. 하 지만 슬링운동군이 대조군에 비해 어깨 통증 감소 차이가 많은 것으 로 보아 실험 기간이 더 길었다면 통계적으로 유의한 차이가 있었을 거라고 생각된다.

본 연구의 제한점으로 대상자 선정기준에 맞는 대상자를 선별하 는데 있어 어려움이 있었다. 또, 입원기간으로 인해 실험기간이 짧았 고 각 군의 대상자 수가 적어 일반화 하는데 어려움이 있었다. 따라서 향후 연구에서는 더 많은 기간과 많은 돌림근띠 봉합술 환자를 대상 으로 슬링운동을 실시한 후 다양한 종속변인에 어떠한 영향을 미치 는지를 확인하는 연구가 필요할 것이다.

\section{참고문헌}

1. Kim JS, Park MC. Changes of shoulder muscles activity during maintaining and lifting shoulder depending on stretch rate of kinesio tape. J Kor Phys Ther. 2015;27(5):299-303.

2. Miller MD, Cooper DE, Warner JP. Review of sports medicine and arthroscopy. J Bone Joint Surg Am. 2002;85(4):771. 
3. Luime JJ, Koes BW, Hendriksen IJ et al. Prevalence and incidence of shoulder pain in the general population: a systematic review. Scandinavian J Rheumatology. 2004;33(2):73-81.

4. Shin SJ. Cross-sectional survey of patients with shoulder pain visiting orthopedic outpatients. J Kor Shoulder Elbow Soc. 2009;5:55.

5. William GB, Mary BB, Michael J et al. Patient outcome following rehabilitation for rotator cuff repair surgery. J Orthop Sports Phys Ther. 2007; 37(6):727-32.

6. Matava MJ, Purcell DB, Rudzki JR. Partial-thickness rotator cuff tears. Am J Sports Med. 2005;33(9):1405-17.

7. Park JH. Diagnosis and treatment of rotator cuff disease. J Shoulder Elbow Surg. 2006;11:69-72.

8. Smith MA, Smith WT. Rotator cuff tears: an overview. J Orthop Nursing. 2010;29(5):319-22.

9. Abrmas JS. Arthroscopic techniques for massive rotator cuff repairs. Techniques shoulder Elbow sur. 2007;8(3):126-34.

10. Kim JY, Chun CH, Kim JW et al. Clinical results of arthroscopic transtendon suture technique of partial articular surface tendon avulsion lesion. J Kor Shoulder Elbow Soc. 2011;14(2):165-71.

11. Rutten MJ, Maresch BJ, Jaqer GJ et al. Ultrasound of the rotator cuff with MRI and anatomic correlation. Eur J Radiol. 2007;62(3):427-36.

12. Cho NS, Hwang JC, Lee YG. Clinical results of arthroscopic repair in fullthickness rotator cuff tears. J Korean Orthop Assoc. 2006;41(5):857-64.

13. Worsley P, Warner M, Mottram S et al. Motor control retraining exercises for shoulder impingement: effects on function, muscle activation, and biomechanics in young adults. J shoulder elbow sur. 2013;22(4):11-9.

14. Kim JH. Rehabilitation of rotation cuff repair. J Korean Arthroscopy Soc. 2008;12(2):82-6.

15. Kim JT, Park SH. Effect of scapular stabilization exercise on EMG change of shoulder girdle and trunk muscle during Archer's shooting. J Sport Leisure Studies. 2009;38(2):1003-10.

16. Baskurt Z, Baskurt F, Gelecek N et al. The effectiveness of scapular stabilization exercise in the patients with subacromial impingement syndrome. J Back Musculoskeletal Rehabil. 2011;24(3):173-9.

17. Ronai P. Exercise modification and strategies to enhance shoulder function. J Strength Cond Res. 2005;27(4):36-45.

18. Jang JH, Goo BO, Kim SY. Serratus anterior muscle exercise for the winging scapula. J Kor Acad Orthop Manual Therapy. 2003;9(2):69-77.

19. Kim SY, Kwon JH. Lumbar stabilization exercises using the sling system. J Kor Acad Orthop Manual Ther. 2001;7(2):1-15.

20. Dannelly BD, Otey SC, Croy T et al. The effectiveness of traditional and sling exercise strength training in women. J Strength Cond Res. 2011; 25(2):464-71.

21. Unsgaard TM, Fladmark AM, Salvesen O et al. Motor control exercises, sling exercises, and general exercises for patients with chronic low back pain: A randomized controlled trial with 1-year follow-up. Phys Ther. 2010;90:1426-40.

22. Sung YB, Nam CW, Lee JH. A comparison of levels of muscle activity based on stabilization exercise methods applied to patients with rotator cuff tendon tears. International J Bioscience Biotechnology. 2016;8(5): 301-10.
23. Kwon OA, Kim YJ, Kwon HM et al. The effects of joint mobilization with combined exercise therapy of sling on post-traumatic adhesive capsulitis patient: a case report. J Kor Proprioceptive Neuromuscul Facilitation Assoc. 2006;4:71-9.

24. Choi EY, Choi $\mathrm{H}$. The effect of exercise using grasping on shoulder muscle activity and muscle thickness of patients with rotator cuff repair. J Kor Phys Ther. 2016;28:52-8.

25. Kang JI, Moon YJ, Park SK et al. Effects of exercise program intervention on muscle activity in rotator cuff repair patient. J Kor Phys Ther. 2013; 25(2):56-63.

26. Wagner DR, Tatsugawa K, Parker D et al. Reliability and utility of a visual analog scale for the assessment of acute mountain sickness. High Alt Med Biol. 2007;8:27-31.

27. Li L, Liu X, Herr K. Postoperative pain intensity assessment: a comparison of four scales in chinese adults. Pain Med. 2007;8(3):223-34.

28. Kim SY. Experimental study about the influence of the different types of joint motion affecting tendon healing after rotator cuff repair. Korea university. Dissertation of Doctorate Degree. 2004.

29. Choi CH, Um DH, Kim SG. Pain \& motion recovery patterns after rotator cuff repair according to tear size. J Korean Orthop Assoc. 2005;40(7): 826-31.

30. Bigoni M, Gorla M, GuerrasioS et al. Shoulder evaluation with isokinetic strength testing after arthroscopic rotator cuff repairs. J shoulder elbow sur. 2009;18(2):178-83.

31. Ellman H, Hanker G, Bayer M. Repair of the rotator cuff. End-result study of factors influencing reconstruction. J bone joint sur. 1986;68(8): 1136-44.

32. Namdari S, Green A. Range of motion limitation after rotator cuff repair. J shoulder and elbow sur. 2010;19(2):290-6.

33. Choi SH, Lee BH, Chung EJ. The effects of stability exercises on shoulder pain and function of middle-aged women. J Phys Ther Sci. 2013;25(2): 155-8.

34. Myung MS. Effect of sling exercises on increase muscles' thickness, function, and range of motion in rotator cuff surgery patients. Dissertation of Master's Degree. 2013.

35. Jang KH, Choi JD, Lee MH et al. A comparison of modified sling exercise and general isometric exercise in patients with shoulder impingement syndrome. J Kor Phys Ther. 2010;22(5):9-16.

36. Park SK, Lee HO, Kim JS et al. A comparison of muscle activity in periscapular muscles during push-up plus exercise on stable support and unstable support. J Kor Acad Orthop Manual Therapy. 2005;11(2):71-82.

37. Jung JH, Cho KH, Yu JH. Effects of scapular stabilizing exercise in patients with partial-thickness rotator cuff tear. J Phys Ther Sci. 2012; 24(11):1173-5.

38. Burkhart SS, Morgan CD, Kibler WB. The disabled throwing shoulder: spectrum of pathology, part I: pathoanatomy and biomechanics. Arthroscopy. 2003;19(4):404-20.

39. Yoon HY, Choi JD. Effects of low-intensity scapular stabilization exercise in arthroscopic shoulder surgery patients. J Kor Phys Ther. 2012;24(3): 229-34. 